\title{
Profil Literasi Fisika Siswa Madrasah Terhadap Mitigasi Bencana Erosi Batang Sinamar
}

\author{
Rizki Zakwandi ${ }^{1}$, Chaerul Rochman ${ }^{2}$, Dindin Nasrudin $^{3}$, \\ Endah Kurnia Yuningsih ${ }^{4}$, Sandijal Putra ${ }^{5}$ \\ ${ }^{1234}$ UIN Sunan Gunung Djati, Bandung, Indonesia \\ ${ }^{5}$ Madrasah Aliyah Negeri, Lima Puluh Kota, Indonesia \\ ${ }^{1}$ rizki.zakwandi@student.uinsgd.ac.id, ${ }^{2}$ chaerulrochman99@uinsgd.ac.id, \\ 32indin.nasrudin@uinsgd.ac.id, 4endahkurnia@uinsgd.ac.id, 55andhi_guru@yahoo.co.id
}

\begin{abstract}
Contextual physics learning with natural phenomena in the environment will be more meaningful for learners. One of the learning contexts that can be raised is the phenomenon of soil erosion in the river Batang Sinamar, West Sumatra. This study aims to describe the profile of physics literacy ability of learners about the erosion of river wall of Batang Sinamar in District of Lima Puluh City of West Sumatera Province. The method used is pre-experimental with one shoot test design. Data collection is done by disseminating instrument literacy consisting of four questions about the process, concept, context and best attitude of learners in response to the phenomenon. The results showed that there were significant differences in literacy ability of physics concepts between students attending school near the erosion site and students who went to school away from the erosion site. The average overall grade of the learners at the closest school is 2.66 and the furthest school is 2.14 . The results of this study can be used as the initial reference in the preparation of enrichment materials about the physical matter related to the phenomenon of erosion of the Sinamar rod wall.
\end{abstract}

Keywords: disaster mitigation, physics concept,science literacy, soil erosion.

Abstrak: Pembelajaran fisika yang kontekstual dengan fenomena alam di lingkungan sekitar akan lebih bermakna bagi peserta didik. Salah satu konteks pembelajaran yang dapat diangkat adalah fenomena erosi tanah di sungai Batang Sinamar, Sumatera Barat. Penelitian ini bertujuan untuk menggambarkan profil kemampuan literasi fisika peserta didik tentang erosi dinding sungai Batang Sinamar di Kabupaten Lima Puluh Kota Provinsi Sumatera Barat. Metode yang digunakan adalah preexperimental dengan one shoot test design. Pengumpulan data dilakukan dengan menyebarkan instrument literasi yang terdiri dari empat pertanyaan mengenai proses, konsep, konteks dan sikap terbaik peserta didik dalam menanggapi fenomena tersebut. Hasil penelitian menunjukkan bahwa terdapat perbedaan kemampuan literasi konsep fisika yang signifikan antara peserta didik yang bersekolah di dekat 
lokasi erosi dan peserta didik yang bersekolah jauh dari lokasi erosi. Rata-rata nilai keseluruhan peserta didik pada sekolah terdekat adalah 2,66 dan pada sekolah terjauh adalah 2,14. Hasil penelitian ini, dapat dijadikan sebagai rujukan awal dalam penyusunan bahan pengayaan tentang materi fisika terkait fenomena erosi dinding sungai batang Sinamar.

Kata kunci: mitigasi bencana, konsep fisika, literasi sains, erosi tanah

\section{Pendahuluan}

Pembelajaran fisika seharusnya diarahkan pada pemahaman fenomena alam. Fenomena alam yang terjadi di lingkungan peserta didik yang diangkat dalam pembelajaran fisika akan jauh lebih bermakna bagi mereka. Selain menguasai konsep, peserta didik juga akan lebih paham terhadap fenomena tersebut. Fenomena alam yang terjadi di lingkungan sekitar dapat dijadikan wahana bagi peserta didik untuk melakukan aktifitas belajar yang lebih original dan alami. Agar pembelajaran fisika lebih optimal, aktivitas belajar peserta didik harus difasilitasi melalui peningkatan interaksi, inovasi dan kreatifitas peserta didik. Dampak pembelajaran fisika yang alami dan bermakna serta kontekstual dengan kehidupan sehari-hari adalah adanya peluang yang lebih leluasa bagi peserta didik dalam memanfaatkan sumber daya alam yang ada di lingkungan mereka ${ }^{1}$.

Kontektualisasi pembelajaran fisika melalui kejadian alam di lingkungan sekitar diharapkan dapat meningkatkan meningkatkan literasi masyarakat dalam memahami fungsi dan perawatan lingkungan. Hal ini bertujuan untuk mengantisipasi dan mempersiapkan masyarakat untuk menghadapi hal-hal yang akan terjadi seperti bencana alam². Salah satu upaya untuk meningkatkan tingkat literasi masyarakat terhadap mitigasi bencana adalah melalui pembelajaran fisika terintegrasi dengan kejadian alam sekitar. Secara sederhana, literasi dalam penelitian ini didefinisikan sebagai seperangkat pengetahuan yang meliputi segala aspek yang dibutuhkan untuk mengoptimalkan fungsi sumber daya alam dan merumuskan upaya perawatan sumber daya alam tersebut. Peningkatkan literasi peserta didik terhadap konsep dan konteks sains dalam fenomena alam

${ }^{1}$ F. A. Al-Maraghi, C. Rochman dan H. Y. Suhendi, "Profil literasi peserta didik terhadap mitigasi bencana gunung berapi di daerah Sukaratu Tasikmalaya," Jurnal Wabana Pendidikan Fisika, Vol. 2, No. 2, 2017. page. 32-35.

${ }^{2}$ S. G. Marlyono, G. K. Pasya dan nandi, "Pengaruh literasi informasi bencana terhadap kesiapsiagaan masyarakat dalam menghadapi bencana di Propinsi Jawa Barat," Jurnal Pendidikan Geografi, vol. 16, no. 2, 2016. page.116-123. 
di lingkungan sekitar diharapkan berkontribusi pada peningkatan literasi sains yang masih rendah. Salah satu penyebab rendahnya literasi peserta didik dalam memahami fenomena alam adalah terbatasnya bahan pembelajaran dan instrumen evaluasi yang sesuai ${ }^{3}$.

Bahan pembelajaran dan evaluasi yang tidak menghadirkan fenomena alam sekitar akan membuat peserta didik menjadi buta akan pengetahuan lingkungan mereka. Bahan pembelajaran dan instrumen evaluasi yang ada saat ini khususnya pada mata pelajaran fisika masih berfokus pada penguasaan konsep, dan formula matematis. Proses pembelajaran fisika yang tidak bermakna pun menjadi faktor penyebab rendahnya literasi peserta didik. Hasil penelitian terdahulu melaporkan bahwa kondisi guru yang memiliki tingkat literasi yang rendah juga akan memicu lahirnya peserta didik yang memiliki tingkat literasi yang rendah ${ }^{4}$.

Salah satu sumber fenomena alam yang dapat diangkat dalam pembelajaran fisika adalah bencana erosi tanah. Bencana erosi biasanya terjadi di bibir sungai dan di daerah muara sungai akibat dari partikel air menumbuk daratan dengan momentum yang besar. Selain itu, kemungkinan terjadinya erosi dinding sungai juga dapat dipengaruhi oleh beberapa faktor seperti topografi, geologi, hidrologi, tanah dan sisa-sisa aktifitas manusia ${ }^{5}$. Fenomena erosi yang menjadi objek literasi pada penelitian kali ini terjadi di sungai batang Sinamar yang bertempat di Jorong Padang Japang Kenagarian VII Koto Talago Kecamatan Guguak Kabupaten Lima Puluh Kota Sumatera Barat. Dari sudut pandang fisika, bencana erosi yang terjadi pada dinding sungai di Batang Sinamar dipengaruhi oleh beberapa konsep fisika diantaranya fluida statis, fluida dinamis, gaya gesek, impuls, momentum dan energi kinetik translasi dari fluida. Dampak yang ditimbulkan oleh bencana erosi sendiri antara lain perluasan bibir sungai, pendangkalan sungai, pergeseran lahan, dan dampak jangka panjang yang akan muncul adalah berkurangnya area daratan karena sudah turun dan menjadi bagian dari sungai. Penelitian ini bertujuan untuk menggambarkan

${ }^{3}$ M. M. Fausan dan I. P. Oujiastuti, "Analisis kemampuan awal literasi sains mahapeserta didik berdasarkan instrumen scientifict literacy assessment," dalam Seminar Nasional Lembaga Penelitian UNM, Makassar, 2017

${ }^{4}$ J. Maknun, "Pembelajaran mitigasi bencana berorientasi kearifan lokal pada pembelajaran IPA di Sekolah Menengah Kejuruan,” Jurnal Kajian Pendidikan, Vol. 5, No. 1, 2015. pp. 143-156.

5S. Purwantara dan M. Nursa'ban, "Pengukuran tingkat bahaya bencana erosi di kecamatan Kokap,” Geomedia, Vol. 10, No. 1, 2012 pp. 111-128. 
kemampuan literasi peserta didik yang ada di lingkungan sekitar sungai Batang Sinamar terkait fenomena erosi tanah.

\section{Metode}

Metode penelitian yang digunakan adalah metode pre eksperimental dengan menggunakan one shoot test design. Pengumpulan data pada penelitian ini dilakukan dengan menggunakan instrument literasi yang terdiri dari empat pertanyaan proses, konsep, konteks dan sikap ${ }^{6}$. Penelitian ini dilakukan pada peserta didik MAS Darul Funun El Abbasasiyah Padang Japang dengan jumlah peserta didik 30 orang sebagai sampel sekolah terdekat dan MAN Kabupaten Lima Puluh Kota dengan jumlah peserta didik 44 orang sebagai sampel sekolah jauh. Data penelitian dianalisis dengan merujuk pada rubrik penilaian dengan rentang skor 0-47 sebagaimana diperlihatkan pada tabel 1 .

Tabel 1. Rubrik Penilaian

\begin{tabular}{|l|l|}
\hline Skor & Kriteria \\
\hline 0 & Jika responden tidak memberikan jawaban \\
\hline 1 & Jika responden memberikan jawaban yang salah \\
\hline 2 & Jika jawaban yang diberikan benar namun tidak lengkap \\
\hline 3 & $\begin{array}{l}\text { Jika jawaban yang diberikan benar, dan lengkap tetapi belum } \\
\text { sempurna sesuai yang diharapkan }\end{array}$ \\
\hline 4 & Jika jawaban sesuai/sempurna \\
\hline
\end{tabular}

Tabel 1 merupakan beberapa pertanyaan dalam penelitian. Kemudian untuk melihat perbedaan nilai literasi dari kedua kelompok subjek penelitian dilakukan uji komparasi dengan menggunakan software SPSS. Hasil pengolahan data kemudian diinterpretasikan sesuai dengan permasalahan penelitian. Secara keseluruhan, analisis data penelitian menggunakan analisis deskriptif nonparametrik ${ }^{8}$.

${ }^{6}$ C. Rochman, D. Nasrudin, Muslim dan N. Hernita, "Characteristics of the ability of physics concept in enrichment teaching materials of natural and mineral resources (NMRs) literacy," Jurnal Pendidikan IP A Indonesia, vol. 6, no. 2, 2017. page. 252-256.

${ }^{7}$ D. Nasrudindkk. MengukurEfektivitas Peer Teaching dalamPembelajaranFisika. 2018. Dipresentasikandalam Seminar Nasional Fisika (SINAFI) UPI Bandung.

${ }^{8}$ C. Rochman, D. Nasrudin dan H. Y. Suhendi, "Profil literasi sains (fisika) peserta didik terhadap sumber daya alam mineral (SDA\&M), energi baru dan terbarukan (EBT) dan mitigasi bencana di wilayah Jawa Barat," dalam Seinar Kontribusi Fisika, Bandung, 2016. 


\section{Pembahasan}

\section{Profil kemampuan literasi sains}

Profil kemampuan literasi peserta didik terhadap mitigasi bencana erosi dinding sungai Batang Sinamar diperlihatkan di tabel 2.

Tabel 2. Profil Kemampuan Literasi

\begin{tabular}{|l|l|l|l|l|}
\hline \multicolumn{5}{|l|}{ Kelompok Nilai } \\
\hline Kelompok & Kualifikasi & $\begin{array}{l}\text { Rentang } \\
\text { Nilai }\end{array}$ & S.Td (\%) & S.Tj (\%) \\
\hline I & $\begin{array}{l}\text { Sangat } \\
\text { Rendah }\end{array}$ & $0,00-1,00$ & 0 & 0 \\
\hline II & Rendah & $1,01-2,00$ & 13,3 & 54,6 \\
\hline III & Sedang & $2,01-3,00$ & 73,3 & 38,6 \\
\hline IV & Tinggi & $3,01-4,00$ & 13,3 & 6,8 \\
\hline
\end{tabular}

Keterangan: S.Td (Sekolah Terdekat), S.Tj (Sekolah Terjaub)

\section{Profil literasi berdasarkan aspek literasi}

Profil literasi dapat ditunjukan berdasarkan aspek-aspek literasi. Hasil pengolahan data terhadap persentase profil literasi peserta didik terhadap bencana erosi diperlihatkan pada tabel 3 .

Tabel 3. Persebaran kemampuan peserta didik berdasarkan Aspek Literasi

\begin{tabular}{|l|l|l|l|l|}
\hline \multirow{2}{*}{ Aspek } & \multicolumn{2}{|l|}{ Rerata Skor (skala 0-4) } & Rerata & $\begin{array}{l}\text { Persentase } \\
\text { Keseluruhan } \\
(\%)\end{array}$ \\
\cline { 2 - 5 } & Sekolah Terdekat & $\begin{array}{l}\text { Sekolah } \\
\text { Terjauh }\end{array}$ & Akhir & \\
\hline Proses & 2,30 & 1,91 & 2,10 & 52,61 \\
\hline Konsep & 2,57 & 1,91 & 2,24 & 55,95 \\
\hline Konteks & 2,83 & 2,05 & 2,44 & 60,98 \\
\hline Sikap & 2,93 & 2,70 & 2,82 & 70,47 \\
\hline Rerata & 2,66 & 2,14 & 2,4 & 60,00 \\
\hline
\end{tabular}

\section{Profil Literasi Berdasarkan Prosentasi Nilai Aspek Literasi}


Profil literasi peserta didik juga dapat dianalisis berdasarkan perolehan nilai kedua kelompok subjek dalam menjawab soal-soal yang berkaitan dengan literasi sains. Hal tersebut dapat digunakan untuk mengidentifikasi aspek mana yang masih memiliki nilai yang rendah untuk kemudian ditingkatkan pada masa yang akan datang. Hasil analisis nilai peserta didik berdasarkan masing-masing aspek diperlihatkan pada tabel 4

Tabel 4. Prosentasi nilai di setiap aspek literasi

\begin{tabular}{|l|l|l|l|l|l|}
\hline \multirow{2}{*}{ Nilai } & \multicolumn{4}{|l|}{ Aspek (\%) } & \multicolumn{2}{l|}{$\begin{array}{l}\text { Rerata } \\
\text { n }\end{array}$} & Proses & Konsep & Konteks & Sikap & \\
\hline 1 & 22,9 & 16,2 & 12,2 & 1,4 & 13,2 \\
\hline 2 & 48,7 & 52,7 & 44,6 & 45,2 & 47,8 \\
\hline 3 & 27,0 & 28,4 & 37,8 & 21,9 & 28,8 \\
\hline 4 & 1,4 & 2,7 & 5,4 & 31,5 & 10,2 \\
\hline
\end{tabular}

\section{Analisis}

\section{Profil kemampuan literasi sains}

Data pada tabel 2, menunjukkan bahwa kemampuan literasi konsep fisika peserta didik pada sekolah terdekat sebagian besar berada pada rentang nilai 2,01 - 3,00 yaitu sebanyak 73,3\%. Sedangan pada sekolah terjauh mayoritas nilai peserta didik berada pada rentang 1,01 - 2,00 sebanyak 54,6\%, dibawah nilai peserta didik sekolah terdekat.Perbedaan tingkat literasi fisika peserta didik mengindikasikan bahwa salah satu faktor yang mendukung tingkat literasi peserta didik adalah pengalaman peserta didik terhadap bencana yang terjadi. Bagi siswa yang bersekolah di sekitar tempat bencana akan lebih mengenal bencana karena terbiasa dengan kejadian disbanding sekolah yang jauh dari lokasi bencana.

Faktor lain yang juga dapat menyebabkan perbedaan nilai yang diperoleh adalah kurangnya informasi terkait bencana kepada peserta didik. Pengalaman yang minim dan kurangnya informasi dapat diatasi dengan beberapa cara yaitu melalui penugasan lapangan, penugasan membaca dan mencari informasi yang relevan ataupun melakukan studi lapangan ke lokasi bencana pada saat terjadinya bencana. Diperolehnya informasi primer melalui pengamatan peserta didik akan menjadi bekal pengatahuan yang lebih kuat. 
Sementara itu pelaksanaan pembelajaran yang mengangkat fenomena-fenomena alam sekitar akan membuat peserta didik menjadi yakin akan pentingya ilmu yang sedang dipelajari. Hal ini akan meningkatkan tingkat literasi peserta didik terhadap bencana yang terjadi dan memberikan nilai pembelajaran yang lebih baik dan kuat.

Hasil penelitian pada tabel 2 juga menunjukkan bahwa tingkat kemampuan literasi fisika peserta didik beragam. Distribusi nilai yang diperoleh oleh peserta didik tersebar pada tiga kelompok yaitu rendah-sedang-tinggi dengan tidak ada satupun peserta didik yang memiliki tingkat kemampuan literasi pada kualifikasi sangat rendah. Secara umum hal ini mengindikasikan bahwa peserta didik cukup baik dalam melakukan penalaran terhadap fenomena yang umum, hanya saja perlu di optimalkan agar bekal penalaran yang sudah bagus dapat memberikan hasil yang memuaskan.Hasil pengujian terhadap kedua kelompok subjek menunjukan bahwa terdapat perbedaan yang siginifikan tingkat literasi di kedua kelompok subjek. Hal ini dinyatakan dengan nilai signifikansi comparasi yang diperoleh sebesar $0,00<0,05$ yang berarti perbedaan antara kedua kelompok subjek adalah sangat signifikan.

\section{Profil literasi berdasarkan aspek literasi.}

Data literasi peserta didik berdasarkan data yang terdapat pada tabel 3dapat dinyatakan dalam bentuk plot berupa grafik 1 sebagai berikut:

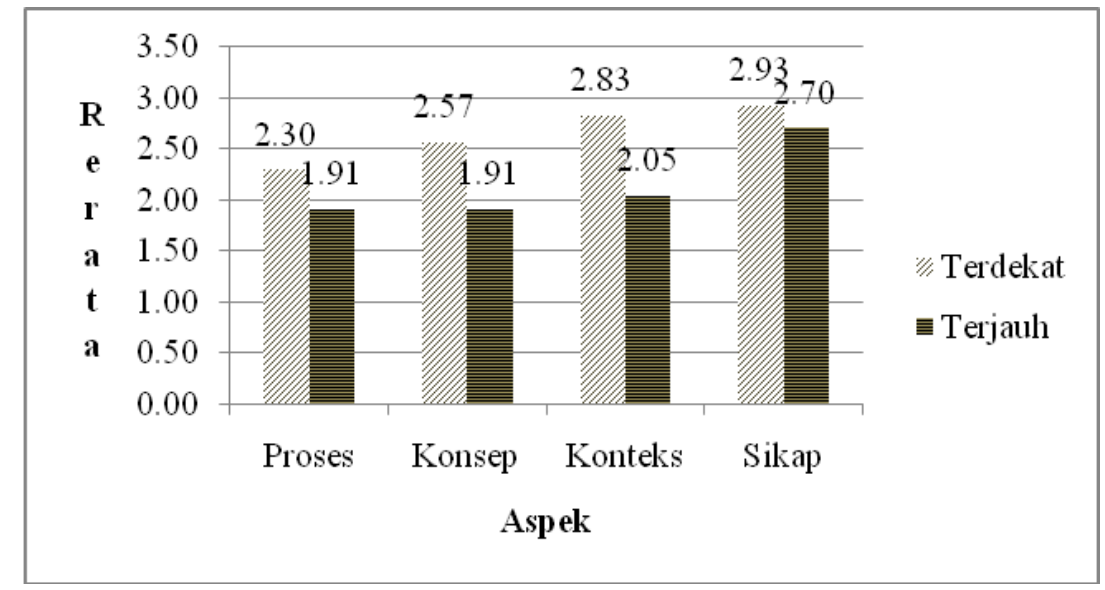

Grafik 1. Pencapaian Aspek Literasi Sains Peserta Didik

Berdasarkan tabel 3 dan grafik 1, diperoleh hasil bahwa perbandingan pencapaian aspek literasi sains peserta didik yang bersekolah di daerah dekat lokasi bencana memiliki nilai yang lebih besar dibandingkan peserta didik yang 
bersekolah di tempat yang jauh dari lokasi bencana. Hasil literasi sains peserta didik diklasifikasikan menjadi lima kelompok dengan rentang sangat rendah $(<20 \%)$, rendah $(21 \%-40 \%)$, cukup (41\%-60\%), sedang $(61 \%-80 \%)$ dan tinggi $(>80 \%)$. Secara keseluruhan tabel3 menunjukan hasil bahwa tingkat literasi sains peserta didik terhadap bencana erosi dinding sungai Batang Sinamar tergolong sedang. Hal ini ditandai dengan respon pengetahuan konteks dan sikap yang sudah mencapai $60,98 \%$ dan $70,47 \%$. Hasil tersebut belum seimbang karena pada pengetahuan proses dan konsep peserta didik baru memperoleh angka capaian 52,61\% dan 55,95\% atau berada pada level cukup.

Berkaitan dengan pembelajaran fisika, temuan penelitian ini masih diluar ekspektasi karena pada dasarnya peserta didik diharapkan dapat memberikan penalaran yang masuk akal terhadap suatu fenomena yang didasarkan pada konsep-konsep fisika yang sudah dipelajari. Hal ini belum terlihat pada pencapaian nilai peserta didik pada aspek literasi yaitu pada sapek proses yang menjelaskan proses terjadinya bencana dan aspek konsep yang merupakan aspek literasi yang sangat berkaitan dengan pembelajaran fisika.Adapun persebaran kemampuan literasi peserta didik pada aspek konsep fisika terdapat pada grafik 2 .

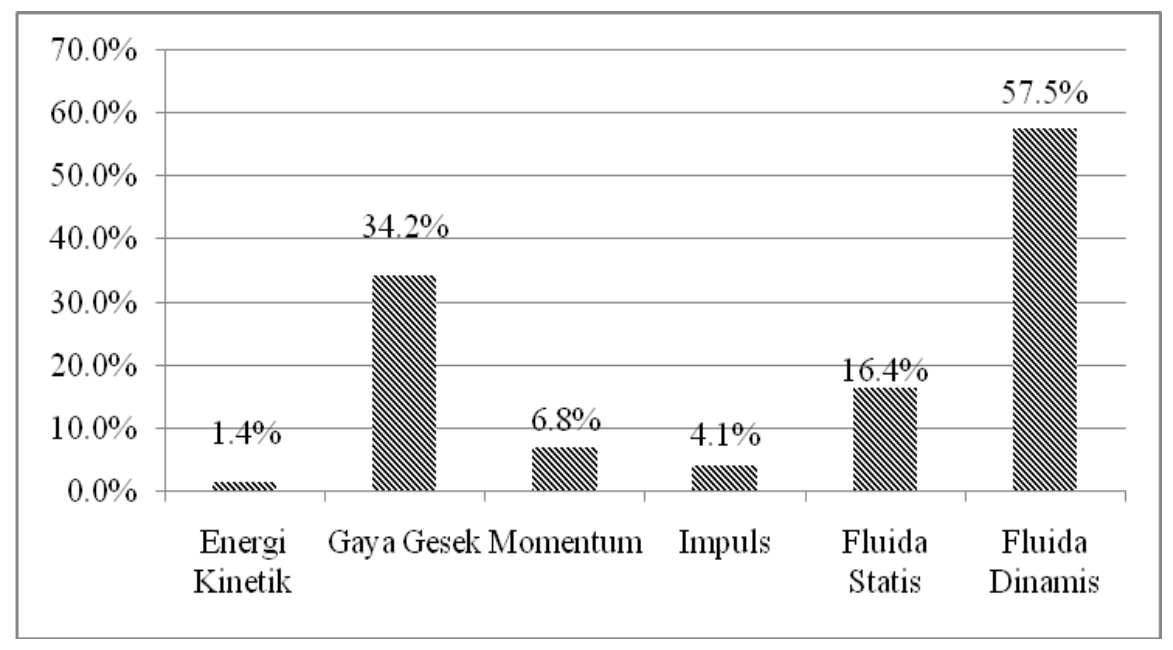

\section{Grafik 2. Pencapaian Aspek Literasi Konsep Fisika Peserta Didik.}

Sebagaimana yang sudah dibahas bahwa pada proses terjadi bencana erosi terdapat beberapa konsep fisika yang terjadi. Berdasarkan sebaran jawaban peserta didik pada grafik 2 peserta didik dominan menganggap bahwa bencana erosi adalah bencana yang hanya di sebabkan oleh fluida dinamis. Hal ini dapat 
dilihat bahwasebanyak $57,5 \%$ peserta didik menyatakan bahwa pada bencana erosi terdapat konsep fluida dinamis dan $34,2 \%$ peserta didik lainnya mendukung dengan ada konsep gaya gesek yang ikut bekerja pada bencana erosi. Grafik 2 mengindikasikan bahwa penguasaan konsep fisika peserta didik belum komprehensif. Hal ini ditunjukkan oleh jawaban peserta didik yang hanya 6,8\% peserta didik yang menyadari konsep tumbukan dan 4,1\% yang menyadari konsep impuls.

Hasil penelitian mengenai kemampuan literasi peserta didik pada aspek konteks dan sikap terbaik peserta didikmenunjukkan hasil berbeda dengan penelitian yang dilakukan oleh Soobard (2011) yang menyatakan bahwa peserta didik mengalami kesulitan ketika memberikan solusi dan keputusan terhadap permasalahan yang dilakukan'. Hasil penelitian yang dilakukan oleh Soobard menyatakan bahwa peserta didik mengalami kesulitan ketika memberikan sikap dan mengambil keputusan untuk menyelesaikan permasalahan lingkungan yang disajikan. Sedangkan pada penelitian ini hasil yang diperoleh mengindikasikan bahwa peserta didik sudah dapat merumuskan suatu sikap terbaik untuk mengatasi permasalahan erosi batang Sinamar. Hal tersebut diindikasikan oleh tingginya skor pencapaian siswa pada aspek sikap konteks dan sikap.

\section{Profil Literasi Berdasarkan Prosentasi Nilai Aspek Literasi}

Berdasarkan data pada tabel 4, terlihat bahwa mayoritas peserta didik memiliki skor 2 di setiap aspek literasi. Aspek pengetahuan proses menjadi aspek yang paling banyak mendapat nilai 1 yaitu sebanyak 22,9\% sedangkan untuk nilai 2 sebanyak 48,7\%. Hasil ini sangat rendah jika dibandingkan dengan perolehan nilai sikap yang mencapai skala 31,5\% untuk nilai 4 dan hanya 1,4\% peserta didik yang memperoleh nilai 1. Jumlah peserta didik yang memperoleh nilai 1 dan 2 pada aspek proses juga berkaitan dengan kemampuan pemahaman konsep peserta didik. Hasil analisis jawaban peserta didik mengindikasikan bahwa mayoritas peserta didik tidak dapat menceritakan atau menggambarkan proses terjadinya bencana erosi dalam sudut pandang fisika. Jika dibandingkan dengan hasil yang diperoleh oleh Almaraghi (2017) yang mana pada penelitian tersebut peserta didik tidak satupun memperoleh nilai 3 dan 4 di setiap aspek literasi, maka dapat dinyatakan bahwa subjek pada penelitian ini lebih literat karena terdapat sebagian kecil dari kelompok subjek memperoleh nilai 4 dan

${ }^{9}$ R. Soobard dan M. Rannikmae, "Assesing student's level of scientific literacy using interdisiplinary scenarios," Science Education International, vol. 22, no. 2, 2011. page. 133-144. 
mayoritas subjek memperoleh nilai 2 dan 3 di setiap aspek literasi ${ }^{10}$. Sebagai gambaran sederhana terkait sebaran nilai literasi peserta didik dapat dilihat pada grafik (sebaran nilai kurva normal) 3:

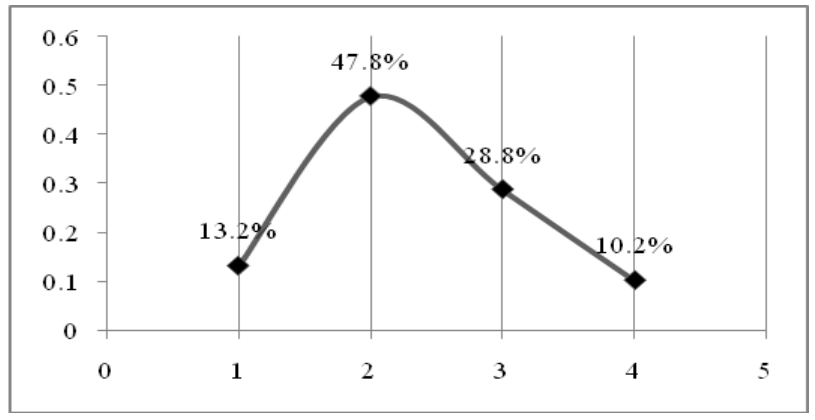

Berdasarkan grafik 3 terlihat bahwa nilai literasi peserta didik memenuhi grafik kurva normal yang mana rerata keseluruhan peserta didik berada pada nilai 2 di setiap aspek literasi.Hal ini dapat dipengaruhi oleh pola interaksi peserta didik dengan lingkungan. Selain itu frekuensi terjadinya bencana juga mempengaruhi tingkat literasi peserta didik terkait bencana tersebut ${ }^{11}$.

Gambaran umum hasil penelitian ini memperlihatkan kondisi dan kemampuan masyarakat dalam menyikapi dan memelihara daratan di sepanjang sungai Batang Sinamar. Hasil penelitian ini juga dapat dijadikan sebagai rujukan awal dalam penyusunan bahan pengayaan tentang materi fisika terkait fenomena erosi dinding sungai Batang Sinamar. Dari hasil penelitan yang dilakukan dapat dilakukan upaya peningkatan kemampuan literasi peserta didik melalui beberapa upaya seperti dengan pengembangan bentuk assessment yang beriorientasi pada literasi sains ${ }^{12}$, pengembangan modul pembelajaran yang berbasis pada masalah terkait fenomena ${ }^{13}$ dan mendesain pembelajaran yang berspektifkan sosial

${ }^{10}$ F. A. Al-Maraghi, C. Rochman dan H. Y. Suhendi, "Profil literasi peserta didik terhadap mitigasi bencana gunung berapi di daerah Sukaratu Tasikmalaya," Jurnal Wabana Pendidikan Fisika, Vol. 2, No. 2, 2017. page. 32-35.

${ }^{11}$ G. Proyowidodo dan J. Luik, "Communicating disaster mitigation literacy to coastal communities in Pacitan, Indonesia," American International Journal of Research in Humanities, Arts and Social Sciences, vol. 5, no. 2, 2014. page. 245-248.

${ }^{12}$ W. P. Astuti, A. P. B. Prasetyo dan E. S. Rahayu, "Pengembangan instrumen assesment autentik berbasis literasi sains pada materi sistem eksresi," Lembaran Ilmu Kependidikan, vol. 41, no. 1, pp. 39-43, 2012

${ }^{13} \mathrm{~A}$. Nisa, Sudarmin dan Samini, "Efektivitas penggunaan modul terintegrasi etnosains dalam pembelajaran berbasis masalah untuk meningkatkan literasi sains peserta didik," Unnes Science Education Journal, vol. 4, no. 3, 2015.page. 1049-1056. 
sains ${ }^{14}$. Harapan akhir dari penelitian ini adalah dapat menyadarkan masyarakat dan peserta didik akan pentingnya memiliki pengetahuan/literasi tentang alam di sekitar tempat tinggal dan dapat mengurangi dan mengantisipasi dampak negatif yang dihasilkan oleh bencana erosi tersebut.

\section{Kesimpulan}

Profil literasi sains peserta didik terhadap bencana erosi dinding sungai batang Sinamar masih tergolong rendah dari aspek pengetahuan proses dan konsep sedangkan tergolong sedang pada aspek konteks dan sikap yang diharapkan. Lemahnya aspek proses dan konsep didasari oleh kurangnya pembahasan dan bahan ajar yang memuat tentang peristiwa tersebut sehingga peserta didik kekurangan bahan untuk memperoleh pengetahuan mengenai hal tersebut.

Berdasarkan hasil penelitian solusi yang dirumuskan untuk meningkatkan literasi peserta didik adalah dengan memperbanyak akses pembelajaran yang berkaitan dengan bencana erosi. Penelitian ini dapat dijadikan sebagai baseline untuk menyiapkan pembelajaran dan bahan pengayaan terkait bencana erosi dinding sungai batang Sinamar.

\section{Bibliografi}

Al-Maraghi. F. A., Rochman. C. dan Suhendi. H. Y, "Profil literasi peserta didik terhadap mitigasi bencana gunung berapi di daerah Sukaratu Tasikmalaya," Jurnal Wabana Pendidikan Fisika, Vol. 2, No. 2, 2017. hal. 32-35.

Astuti. W. P., Prasetyo. A. P. B. dan Rahayu. E. S, "Pengembangan instrumen assesment autentik berbasis literasi sains pada materi sistem eksresi," Lembaran Ilmu Kependidikan, vol. 41, no. 1, hal. 39-43, 2012

Nasrudin, Dindin dkk. Mengukur Efektivitas Peer Teaching dalam Pembelajaran Fisika. 2018. Dipresentasikan dalam Seminar Nasional Fisika (SINAFI) UPI Bandung. 2018

Fausan. M. M. dan Oujiastuti. I. P., "Analisis kemampuan awal literasi sains mahapeserta didik berdasarkan instrumen scientifict literacy assessment," dalam Seminar Nasional Lembaga Penelitian UNM, Makassar, 2017

${ }^{14}$ M. Hernani, A. Mudzakkir dan S. Aisyah, "Membelajarkan konsep sains-kimia dari perspektif sosial untuk meningkatkan literasi sains peserta didik SMO," Jurnal Pengajaran MIP A, vol. 13, no. 1, pp. 71-94, 2009. 
Hernani. M., Mudzakkir. A. dan Aisyah. S, "Membelajarkan konsep sains-kimia dari perspektif sosial untuk meningkatkan literasi sains peserta didik SMO," Jurnal Pengajaran MIP A, vol. 13, no. 1, hal. 71-94, 2009.

Iswadi. H, "Sekelumet Dari Hasil PISA 2015 yang Baru Dirilis," Universitas Surabaya, 07 Desember 2016. [Online]. Available: http://www.ubaya.ac.id/2014/content/articles_detail/230/Overviewof-the-PISA-2015-results-that-have-just-been-Released.html. [Diakses 08 Nopember 2017].

Maknun. J, "Pembelajaran mitigasi bencana berorientasi kearifan lokal pada pembelajaran IPA di Sekolah Menengah Kejuruan," Jurnal Kajian Pendidikan, Vol. 5, No. 1, 2015. hal. 143-156.

Marlyono. S. G, Pasya. G. K dan nandi, "Pengaruh literasi informasi bencana terhadap kesiapsiagaan masyarakat dalam menghadapi bencana di Propinsi Jawa Barat," Jurnal Pendidikan Geografi, vol. 16, no. 2, 2016. hal.116-123.

Nisa. A., Sudarmin dan Samini, "Efektivitas penggunaan modul terintegrasi etnosains dalam pembelajaran berbasis masalah untuk meningkatkan literasi sains peserta didik," Unnes Science Education Journal, vol. 4, no. 3, 2015. hal. 1049-1056.

Proyowidodo. G. dan Luik. J., "Communicating disaster mitigation literacy to coastal communities in Pacitan, Indonesia," American International Journal of Research in Humanities, Arts and Social Sciences, vol. 5, no. 2, 2014. hal. 245-248.

Purwantara. S. dan Nursa'ban. M, "Pengukuran tingkat bahaya bencana erosi di kecamatan Kokap,” Geomedia, Vol. 10, No. 1, 2012 hal. 111-128.

Rochman. C, Nasrudin. D, Muslim dan Hernita. N, "Characteristics of the ability of physics concept in enrichment teaching materials of natural and mineral resources (NMRs) literacy," Jurnal Pendidikan IP A Indonesia, vol. 6, no. 2, 2017. hal. 252-256.

Rochman. C, Nasrudin. D dan Suhendi. H. Y., "Profil literasi sains (fisika) peserta didik terhadap sumber daya alam mineral (SDA\&M), energi baru dan terbarukan (EBT) dan mitigasi bencana di wilayah Jawa Barat," dalam Seinar Kontribusi Fisika, Bandung, 2016.

Soobard. R. dan Rannikmae. M, "Assesing student's level of scientific literacy using interdisiplinary scenarios," Science Education International, vol. 22, no. 2, 2011. hal. 133-144. 